\title{
Prof. João Cabral
}

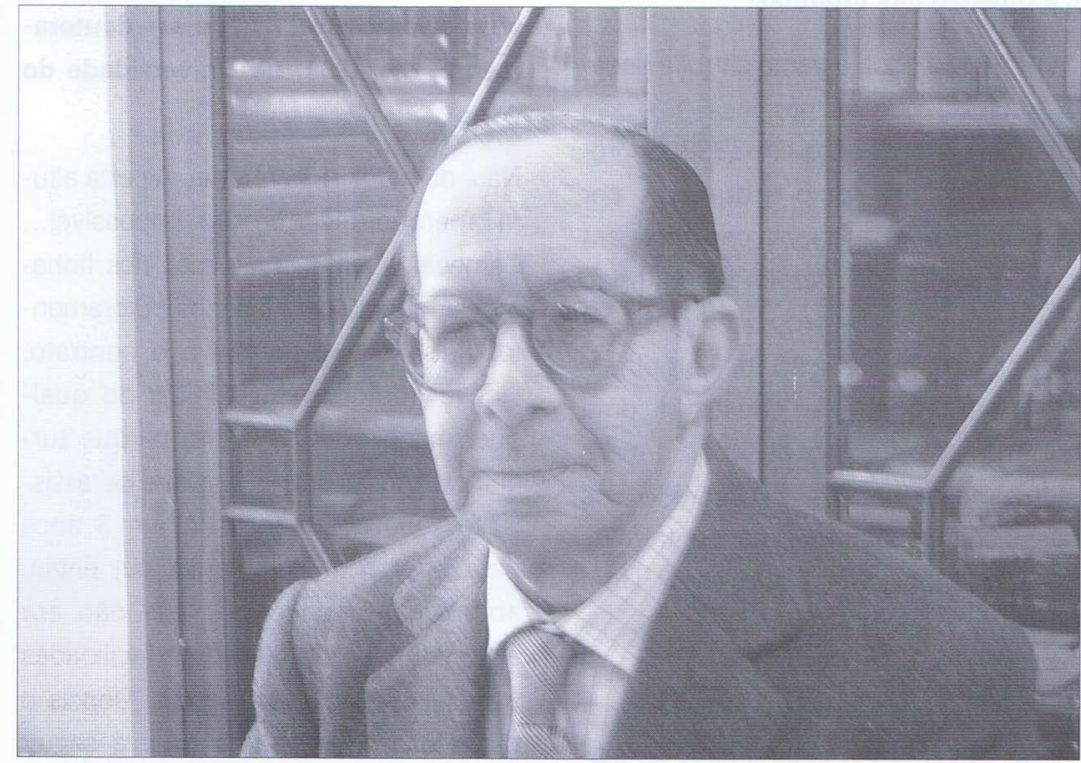

Professor João Cabral, qual era sua opinião sobre a Química, e sobre o que se fazia em Química, quando iniciou a sua carreira?

A carreira ou os estudos universitários?

\section{Ambas se desejar.}

É que eu entrei para a Universidade em 1938. Era uma época um bocado conturbada porque já se adivinhava que ia haver guerra. E a guerra civil de Espanha ainda não tinha acabado. De Química propriamente eu tive um percurso que não foi, por assim dizer, muito directo... porque eu não entrei para Engenharia. Entrei para os Preparatórios militares de Engenharia. Fiz os meus três "aninhos" que aquilo requeria e, depois, o meu pai deve ter mexido certos cordelinhos, porque quando fui à inspecção militar... entrei e saí... (risos...).

\section{Isso foi uma vantagem?}

Foi, antes disso eu nunca tinha pensado na vida; e foi nessa altura que decidi mudar para Engenharia Química.

Porque nessa altura a Química lhe parecia uma coisa útil?

Sim sim. Diziam-me que era uma coisa que tinha futuro.

\section{Que tinha saída profissional?}

Exactamente. O que sucedia era que me faltavam muitas Químicas. Eu não podia ir para Engenharia Química sem ter...vejamos o que me faltava... Química Inorgânica, Química Orgânica, Química-Física e Análise Quantitativa.

\section{Faltava um bocadinho...}

(Risos..), pois o resto não tinha. Tinha uma Química Geral que não valia nada para o caso, e uma Análise Química Qualitativa. Exceptuando o caso do Técnico, onde nessa altura eram professados os seis anos completos de Enge- nharia, aqui no Porto, na Faculdade de Engenharia, como noutros sítios do País era necessário ter os chamados, preparatórios de Engenharia, que eram os três primeiros anos. Felizmente para mim, infelizmente para outros, havia uma disposição legal que permitia, para acabar um curso, fazer todas as disciplinas que se quisesse sem atender a precedências. A situação era muito mais simples, em certos aspectos, que a actual.

Mas não precisava sequer de ter autorização de um Professor para frequentar os cursos?

Não, não! estava escrito na lei, era o meu direito.

\section{Mesmo aulas de laboratório?}

Sim, sim. O Professor tinha de me aturar..(risos...), o que até era engraçado; a Química-Inorgânica era do $1 .^{\circ}$ ano e a Química-Física do $4 .^{\circ}$ ano. Eu estava a frequentar disciplinas do $1 .^{\circ}$ e do $4 .^{\circ}$ ano simultaneamente. 0 professor dessas disciplinas, que era uma pessoa intelectualmente um bocadinho fraca, não conseguia compreender aquilo.

Gostaria de lhe colocar ainda uma outra pergunta clássica...

Mas espere... isto era acerca da opinião sobre a Química. O que eu posso dizer é que a Química na Faculdade de Ciências, e eu apanhei todas as disciplinas, estava ainda no tempo do Ferreira da Silva...

Em que sentido?...O Ferreira da Silva já não está vivo, morre em...

...morre em 1922

Quer dizer que não se fazia investigação... 
O que é isso? (risos....... não sabiam, sabiam lá o que era. Não, eu digo isto por causa dos livros. Os livros eram livros muito bons, na época, mas naquela altura tudo aquilo já estava totalmente desactualizado. Eu tinha a sensação que sim, mas não tinha uma certeza; achava que era fracote. Mas na Faculdade de Engenharia era pior...

Tinha a sensação que os meios eram muito primitivos?

Eu não sei se noutros sítios do País seriam muito melhores. Mas, na altura, já podia ter havido outro avanço, porque mesmo com dificuldades, o que é facto é que, os espanhóis tomaram-nos logo ali a dianteira. Havia livros norte-americanos que eles traduziram. Nós usávamos esses livros traduzidos para o espanhol. E também era já altura em que Kolthoff ${ }^{1}$ era dono e senhor; e Kolthoff não era nenhum banana. A Faculdade de Engenharia era pior; eu dou-Ihes um exemplo. Havia um professor que dava aulas, suponhamos, das $15 \mathrm{~h}$ às $16 \mathrm{~h}$, e das $16 \mathrm{~h}$ às $17 \mathrm{~h}$ havia, suponhamos, Resistência de Materiais. Ele chegava pelas $15 \mathrm{~h}$ e levava uma hora a encher nos quadros pretos, tudo o que iria dar. Portanto, entrava pela outra aula quando propriamente começava a sua aula. E nós não podíamos estar em dois sitios ao mesmo tempo. Havia, assim, umas coisas completamente inconcebíveis; se fosse agora não sei?... começava uma greve ou punham cadeados nos portões...(risos...). Nós fazíamos uma coisa muito simples, éramos muito poucos em Engenharia Química. Éramos 4. Havia rotativamente um voluntário que ficava para a aula, e os outros que quisessem iam para a teórica de Resistência de Materiais, porque as teóricas não eram obrigatórias... e continuam a não ser.

\section{Mas as práticas eram obrigatórias?}

Eram sim senhor, não se podia dar mais do que um certo número de faltas. .

No fundo nessa altura a Química já era um ciênca experimental...

Nessa altura era, embora a parte experimental fosse um bocadinho antiquada, nós tinhamos os laboratórios..mas tam- bém tínhamos oficinas de carpintaria e serralharia.

\section{Como eram engenheiros...}

ah! pois é...(risos...)

O trabalho que nós tivemos em carpintaria era fazer uma tábua de lavar roupa... O que era grave é que a nota que nós tivéssemos era igual a uma nota de Resistência de Materiais ou de uma Química Industrial, valia o mesmo.

\section{E a questão das propinas?}

As propinas? Toda a gente daqui e dacolá, protesta que as propinas hoje são uma barbaridade. Ora em 1938 as propinas eram um conto e duzentos por ano, mais cem escudos por ano para cada cadeira de indole laboratorial. Havia isenção de propinas, podia-se requerer uma isenção de propinas, podia-se requerer e conseguir uma bolsa de estudo, isso dependia fundamentalmente das classificações e das possiblidades económicas da família Sabe quanto custava um café? Uma bica?

\section{Um escudo?}

Sessenta centavos. Sabe quanto ganhava um assistente nessa altura?... Um conto e quinhentos por mês. O que seria se nós passássemos esse conto e trezentos $(1.200+0.100$ contos) para agora? O dobro do que aquilo que as Universidades estão a cobrar, à vontadinha

Professor João Cabral tendo sido licenciado e Doutorado em Engenharia Química, vem dar aulas na Faculdade de Ciências.

Ah! isso...De facto a Engenharia Química tinha muita saída. Havia as minas durante a guerra. Depois é a recessão e as saídas desapareceram, já não havia. O volfrâmio, por exemplo, deu um enorme desenvolvimento à Química Analítica, até mesmo à Engenharia Química Em especial os alunos de Engenharia de Minas, que estavam a entrar às catadupas, ficaram completamente descalços. Quando acabei o curso, o último ano da licenciatura, sucedeu que abriu um concurso na Faculdade de Ciências para entrada de assistentes. Concorri e fiquei. Foi o que me surgiu. E não estou arrependido.

Professor Cabral a sua primeira saída foi para Manchester, salvo erro, em 1949 , onde estudou polagrafia de corantes azóicos sobre orientação do Professor Turner..

Não, não era Professor, nem Doutor, tinha um mestrado.

... O que eu gostaria de lhe perguntar é, se não tivesse ido para Manchester teria sido possível fazer o seu doutoramento, em 1951, na Universidade do Porto?

Não, de maneira nenhuma. A certa altura apercebi-me que era impossivel... Comecei a tentar aqui, mas nós tinhamos um prazo para fazer o doutoramento, findo o qual acabava o contrato. Houve doutoramentos feitos de qualquer maneira nessa altura, porque surgiu a disposição legal em que os assistentes não doutorados tinham 3 anos para fazer o doutoramento, ou, então, abandonar a docência. Isto não era acompanhado de quaisquer facilidades para fazer os doutoramentos. Depois o prazo passou para 4 anos e a seguir para 6, porque, pelo menos no campo da Química, praticamente não havia condições. Havia algumas coisas sobre a parte da análise Química ainda ligada ao estanho ou ao volfrâmio. A única excepção foi o Doutor Humberto de Almeida que fez o doutoramento nos 3 anos; ele, de facto, fazia trabalho, mas no Instituto do Vinho do Porto. Muita gente na Universidade torcia o nariz, por aquele senhor estar a fazer o trabalho no IVP.

\section{Porque era investigação aplicada?}

Porque não era Universidade. 0 trabaIho dele era bastante bom, era por questões de qualidade no vinho do Porto, por exemplo, conter ou não conter chumbo. O problema foi posto pelos ingleses que rejeitaram caixas de vinho do Porto, porque tinha um teor em chumbo superior ao que eles aceitavam: seria por causa das rolhas, das cápsulas? O problema era grave. O Instituto de Vinho do Porto tinha de tratar daquilo, e ele pegou no caso e foi ver em whisky, nisto, naquilo, 
naqueloutro e verificou que o vinho do Porto tinha menos chumbo do que aquelas bebidas. Problema resolvido. Daquilo nunca mais se ouviu falar. Portanto, académico ou não académico, era útil. Para além disso, o trabalho para os meios de que ele dispunha era bastante bom.

Retomando a sua pergunta sobre o meu doutoramento, entre outras coisas, orientação não existia, e então pensei, "vamos lá ver se me consigo lembrar de alguma coisa". O melhor era tentar ir para fora do País, mas não para Espanha. E foi nessa altura que eu pense em ir para Inglaterra. Procurei saber que possibilidades havia do Instituto de Alta Cultura me poder dar uma bolsa para me ir preparar para Inglaterra. Bateram-me com a porta na cara. Quando eu fiz a pergunta, a resposta foi esta, "Nem pense nisso". Havia umas tricas por trás, e eu estava, como se diz, "a comer por tabela". Como o British Council oferecia bolsas, eu tentei o British Council; aliás eu estava a frequentar o Instituto Britânico no Porto. Em 1948 eles ofereciam três bolsas, tendo eu ficado em terceiro lugar. Mas fui um pouco imprudente na candidatura, na escolha do tema. Fiquei em terceiro, mas a resposta foi, "nós vamos chamar o quarto porque não encontramos sítio no Reino Unido onde esse tema seja estudado".

\section{Qual era o seu tema?}

Aproveitamento dos resíduos da indústria de papel. Recomendaram-me que concorresse segunda vez. Concorri em 1949, fiquei em primeiro lugar, e nessa altura já pus um leque muito amplo.. Mas perguntou porque é que fui parar a Manchester. Eu dava aulas práticas de Química Analitica e tinha uma certa experiência. Sucedeu que o Sr. Turner, que apesar de não ter nenhum grau além de mestre, orientava doutoramentos, se interessou pela minha candidatura, (donde se conclui que grau e mérito não são bem coincidentes. Podem ser ou não ser). O Director de Departamento, que era um gentleman da cabeça aos pés, também só tinha o mestrado, e toda a gente Ihe tinha muito respeito. Sucedera que o Sr. Turner tinha ido a uma confe- rência; andavam nessa altura a fazer uns trabalhos sobre Química-Física de tinturaria; havia um corante que era utilizado como um dos padrões para efectuar essas medições. Faziam-se medições colorimétricas. Ainda com aqueles colorímetros antigos, embora fosse já um fotocolorímetro com registo fotográfico; em aparte "quem nunca fez isso não sabe o que é bom" (risos...). E falou-se na polagrafia de corantes azóicos. Cá está, pensei eu, então é isto. Mas o Sr. Turner sabia tanto de polagrafia como eu, embora já tivessem comprado um polarógrafo de registo fotográfico. 0 primeiro período foi completamente perdido para qualquer trabalho, foi a aprendizagem. E esta aprendizagem teve um aspecto curioso: é que eu consegui umas rectas de lei de Ohm maravilhosas (risos...). Estivemos ali a magicar naquilo, e sabe o que era? O eléctrodo de referência era uma camada de mercúrio no fundo de uma célula de vidro, e o contacto era feito por um fio de platina; naquelas células que nos tinham fornecido o fio de platina não entrava em contacto com a solução, de maneira que, aquilo que estávamos a medir era só uma resistência. A fábrica trocou tudo e pôde-se começar o trabaIho.

Volta então a Portugal para concluir o seu doutoramento...

Não, não. Estive lá em 1948/49. Em 1949, o director do Departamento que era um Departamento de Química Têxtil, perguntou-me se eu gostaria de continuar mais um ano, porque isso talvez desse para fazer lá o doutoramento. Eu disse, sim senhor, encantado da vida, mas daqui (do Porto) responderam-me, "regresse porque precisamos de si para os exames de Outubro".

\section{O Professor João Cabral acaba de fazer o seu doutoramento em 1951..}

Foi, foi. Sabe quanto demorou desde que entreguei a tese até fazer as provas...o tempo normal de uma gestação nove meses (risos...)

\section{Como eram constituídos os júris de doutoramento?}

Os júris de doutoramento eram compostos por todos os professores catedráti- cos, fossem do que fosse. Tinha no meu júri professores de Engenharia Civil, Engenharia Mecânica, Engenharia Electrotécnica, só havia um de Engenharia Química e depois foram buscar um professor de Química. Todos tinham o seu voto, todos davam uma nota.

E havia arguência, havia uma apresentação?

Ora bem, variava. Eu tinha hipótese de fazer o doutoramento ou na Faculdade de Ciências ou na de Engenharia. Se eu fizesse o doutoramento na Faculdade de Ciências tinha de ser em Ciências Físico-Químicas; e havia 12 pontos para interrogatório 6 de Física e 6 de Química. Eu não estava minimamente habilitado para as perguntas de Física. A licenciatura em Fisico-Químicas tinha mais Física do que a que eu tinha tido. Fui escolher, portanto, o doutoramento na Faculdade de Engenharia, onde tinha uma prova prática, laboratorial; e essa prova prática foi um dos motivos pelo qual recusei todos os convites posteriores para ir para a Faculdade de Engenharia. A prova prática era a seguinte, deram-me um frasquinho, com uma amostra para dosear ferro, carbono, enxofre e fósforo. E disseram-me "tem aqui um laboratório à sua disposição para fazer a análise" ... o laboratório estava vazio... só tinha bancadas, poucos reagentes, não tinha soluções nem água destilada. Pedi água destilada e responderam-me... "não temos". Felizmente que a Faculdade de Ciências era perto e eu trazia a água destilada de lá.

\section{Quanto tempo é que o Professor tinha} para fazer essas provas?

Praticamente sem limite, não mais de uma semana...(risos...). Para dosear carbono, que se fazia por combustão, o forno estava estragado, não funcionava, mas o doutoramento correu sem problemas, excepto este da prova laboratorial.

Professor Cabral, uma outra questão: em 1953 está no M. I. T., não é verdade?

Deixe-me ainda dizer outra coisa, acerca do período em Manchester. Em 1949 ainda se estava em pós-racionamento. A certa altura o papel fotográfico que se 
usava para enrolar no cilindro, fazer a fixação e revelação, esgotou-se. Disseram-me "tome uma requisição em branco e veja se por ai consegue arranjar". Consegui umas folhas maiores, tinha que ir para a sala escura cortar às dimensões do cilindro. Lá me arranjei...

Então respondendo ao M.I.T. A ida ao M.I.T. foi com uma bolsa deles (EUA). Era algo que eles tinham muito bem esquematizado; os estudantes finalistas da parte de administração e gestão, tinham de organizar o período de férias de pós-graduação, administar os dinheiros, fazer isso tudo. Candidatei-me e foi lá que conheci o Alberto Ralha²; em Cambridge, Massachusetts,

O Professor João Cabral trabalhou em polarografia no M.I.T. com o Dr. Hume e depois regressa a Portugal...

pois eram só seis meses...

Volta a Portugal, uma Nação pobre e isolada do mundo. O que é que sentiu quando fez a inevitável comparação.

Primeiro aquilo era duro; correcto, leal, mas duro. As pessoas tinham de mostrar que eram capazes. Quando cheguei lá, já estava planeado que iria trabalhar com o David Hume. Ele disse-me "estou interessado neste problema assim as$\mathrm{sim}^{3}$, as constantes obtidas são muito divergentes. Tanto se pode obter $10^{-40}$ como $10^{-50}$. Os valores são muito pequenos e como tal dificeis de determinar. Arranjei uma equação para poder resolver este problema. Desejo que faça o mesmo para podermos comparar." Deu-me uma semana, durante a qual se ausentou. Era duro. Creio que se não tivesse conseguido não teria havido problema. Mas ele pôs-me à prova. Quando do seu regresso perguntou "então conseguiu?" ...consegui! "Então vamos comparar". E era a mesma, embora aparentemente diferente.

Quando me vim embora, (não cheguei ao fim) disse-me para deixar cópia de todos os polarogramas. E eu deixei. Passado um tempo recebo uma carta dele, que dizia "como sabe o seu trabalho não está terminado e eu tenho aqui um estudante de doutoramento que o vai continuar. Devo dizer que os seus resultados são todos reprodutíveis." O indivíduo foi reproduzir os trabalhos (risos...), foi cómico, mas ficámos amigos.

O Professor Cabral teve boas condições de trabalho tanto em Manchester como no M.I.T

sobretudo no M.I.T.

E no Porto a vida era muito mais dura.

Era era...

Quer-nos contar um pouco das condições de trabalho dessa época ( no Porto).

...e o número de horas de aula que era necessário dar. 0 mínimo era 12 , por semana. Eu cheguei a ter 30.

\section{Por semana?!}

Sim senhora. E estou vivo (risos...). Os meus trabalhos não tiveram aqui grande aceitação.

A sua tentativa de fazer investigação? Sim, sim.

Como é que o Prof. Cabral explica isso?

Como explico? Porque cheguei à conclusão e disse-o várias vezes, que ninguém pode.fazer polarografia sem polarógrafo (risos...). Pois sim, mas não havia dinheiro. Eu andava assim um bocado de candeias às avessas com determinadas pessoas. Não aceitava as coisas que eram feitas. Logo de início peguei-me com o que em 1942 tinha sido meu professor em Química-Física, nas aulas teóricas. Não podia aceitar aquilo, e não me calava

Na Universidade não havia então um espírito que motivasse a fazer investigação?

\section{Não, não}

\section{Mesmo com provas já dadas?}

Dizia-se "então já tem o seu doutoramento, que mais é que você quer?"

A certa altura que houve um certo dinheiro, que poderia ter dado para um início, para comprar o polarógrafo. "Não, não" disseram-me. "Porque Coimbra tem um espectrofotómetro, vamos comprar um espectrofotómetro". Virei-me para quem o disse e retorqui "Então nós vamos comprar um espectrofotómetro porque Coimbra tem um? Eu era capaz de dizer a coisa ao contrário, como Coimbra tem um espectrofotómetro, que nós podemos usar, não compramos o espectrofotómetro, gastamos o dinheiro numa coisa que Coimbra não tenha." Mas a resposta foi, "É o espectrofotómetro!" E assim foi. E quem o usou foi um espanhol que estava a fazer um estágio em Farmácia.

Qual era o espectrofotómetro?

Era um Beckmam DU

Naturalmente ainda funciona?

Poderia funcionar. Uma óptica impecável, poderia funcionar.

Tínhamos uma ideia que as coisas tinham sido difíceis, mas não sabiamos que tivessem sido tão difíceis. Sinceramente.

Depende dos sítios

No Técnico...

Não, no Técnico era diferente. Bastava lá estar o Prof. Herculano de Carvalho.

Uma outra fase da sua carreira parece resultar da sua estada em Belfast em 1963 e 1964 com o Prof. Nelson em Química de coordenação de complexos moleculares mistos de cobalto(II) com halogénios e aminopiridinas. Foi muito importante para si essa estada?

Foi, foi. Havia vagas de Prof. Extraordinário. Não sei se sabem, o concurso para Professor Extraordinário exigia uma dissertação. Portanto eu tinha de elaborar uma dissertação mas aqui (no Porto) não havia hipótese alguma. Não havia condições. O Beckman DU não dava para dissertação de coisa alguma. Concorri à Gulbenkian, a uma bolsa de estudo. Mudei de agulha por completo.

Mas escolheu o Professor Nelson por já conhecer os seus trabalhos?

Não. Eu até supunha que ia trabalhar com outro. Nós ficámos íntimos. Eu ia lá para casa dele e ele vinha cá, para a minha, com a família. Dizia-se que nós éramos o ramo Português da família Nelson, e eles o ramo Irlandês da famí- 
lia Cabral. Tínhamos relações melhores do que se fosse família. O Martin Nelson era um indivíduo com uma percepção, uma intuição como eu nunca vi. Tenho lidado com muita gente, mas com aquela percepção dele nunca vi.

Essa primeira estada foi o início de uma colaboração que continuou até ele morrer. Aliás, depois mais para a frente, foi possivel associar electroquímica, voltametria com a parte de compostos de coordenação

É curioso que ainda se nota actualmente na investigação que o seu Departamento faz, as estradas que o Professor Cabral lançou...

Há uma coisa que é a minha coroa de glória aqui dentro: foi ter aberto caminho para outros. Como eu tinha encontrado muitas dificuldades, quando tive possibilidades pensei: vamos abrir o caminho para outros.

Professor Cabral, no seu texto inserido no livro "Faculdade de Ciências da Universidade do Porto 1911-1986. Os primeiros 75 anos" refere em termos muito elogiosos o Professor Mendonça Monteiro, como alguém que deixou uma herança de bem fazer.

Marcou um período nítido na Química da Faculdade de Ciências a passagem dele a Director do Laboratório (1949). Foi uma mudança radical. E como ele era o meu mestre, a pessoa com que eu lidava, nós entendiamo-nos maravilhosamente. Era uma pessoa não muito sabedora, um bocadinho preguiçoso, mas extremamente inteligente. Quando ele decidia que ia estudar um assunto, calma, que ficava mesmo bem estudado. E era uma pessoa de ideias largas. De maneira que aquilo foi uma mudança radical de uns medíocres, para uma pessoa, pelo menos altamente inteligente.

O Professor João Cabral sente-se um pouco herdeiro dessa forma de dirigir o laboratório?

Em certa medida sim. Porque ele deume carta branca em muita coisa.

Neste mesmo livro, o Prof. João Cabral transcreve alguns excertos do decreto lei de Julho de 1964, que lança as bases de uma reestruturação do ensino científico (uma necessidade premente uma vez que a anterior datava de 1911). Esse decreto recomenda que não se proceda a uma precoce especialização, mas pelo contrário se aumente e aprofunde a cultura geral do licenciado, prolongando-se por mais um ano as licenciaturas. A actual tendência é precisamente o inverso: diminuir e especializar. Quer comentar?

A minha opinião sobre isso é que está errado, fundamentalmente errado. A especialização vem depois, se não há bases a especialização fracassa, ou é uma fantasia. Só para dar um exemplo de uma coisa actual. Só no $12 .^{\circ}$ ano se fala em logaritmos. Mas no $100^{\circ}$ ano ou no 9. dá-se pH. Para um Químico não é preciso dizer mais... (risos...).

Diz-se que o ensino Universitário era elitista; sobre isso não sei. O que penso, posso estar errado, é que o ensino universitário não é para todos. É para quem for intelectualmente capaz e for suficentemente trabalhador. Veja os Americanos, são duros, mesmo para sacudir. Não é por diletantismo é para trabalhar duro. No M.I.T. estava a estudar um português, filho de uma gente com muito dinheiro. Estava a estudar Química Orgânica, tinha reprovado no exame, e tinha mais uma hipótese num exame de recurso, caso contrário... fora do M.I.T.

É unânimemente reconhecido que a Faculdade de Ciências da Universidade do Porto fica marcada pela sua visão estratégica, nas décadas de 60 e 70, no que respeita à política de doutoramentos. Poderia ter optado por construir um grande grupo, mas optou por diversificar e criar condições para que os novos doutores iniciassem as suas linhas de investigação. De certa maneira foi uma pessoa generosa de grande visão.

Acho que não. Uma pesssoa que chega a um determinado lugar tem um certo número de obrigações. E deve notar aquilo que falta e ver como remediá-lo. Sim, não é só dizer que se tem um título de Professor Catedrático. Eu não sei se poderia ter criado um grupo forte ou não. Mas não tinha interesse especial nisso, porque havia outros interesses; havia áreas que estavam completamente desertas. Não havia ninguém que de facto se tivesse dedicado a Química-Física, foi depois o Ribeiro da Silva a fazê-lo. Não havia ninguém na Química Teórica, que estava a começar, era preciso arranjar alguém com cabeça para se dedicar a tal. Foi o Alberto Amaral e depois o Ferreira Gomes. Mesmo na parte de Química Inorgânica, eu estava para uma banda e fugia com um pézinho para a electroquímica, era preciso uma pessoa, que foi o Adélio Machado.

E como é que escolhia os supervisores?

De uma maneira muito simples. Eu ia aos congressos, e encontrava um certo número de professores, e pensava... este seria um bom orientador...e perguntava: "Você importar-se-ia de ter um português como estudante de doutoramento?" Respondiam-me que dependia das verbas. Ao que retorquia: "Não precisa de ter verbas para o sustentar, ele vem com bolsa de estudo...". E foi assim. Dei as oportunidades, acho que cumpri a minha obrigação.

Outra coisa pela qual já fui censurado, por isso podem-me censurar à vontade

. O Aquiles que se doutorou comigo (só doutorei duas pessoas), publicava um artigo ou outro. A certa altura proibi-o de pôr o meu nome no artigo. "Você não põe o meu nome no artigo. Está proibido". "Mas porquê?"... "Sabe, é porque eu sou muito mais conhecido que você, e se aparece o meu nome no artigo... é meu, não é seu."

Já ouvimos dizer que a Química actual está em fase de grande criatividade, como o contrário. Qual é a sua visão sobre o estado actual da Química?

Se a Química não progredisse estávamos bem arranjados, era porque não prestávamos para nada. Há muito progresso, creio no entanto, que em certos aspectos, é progresso demais. Não gosto que as máquinas mandem em mim. Nisso sou um pouco bota de elástico. De maneira que não compreendo Síntese Química por computadores... (risos...) 
Sim senhor, então agora vai lá buscá-lo, traz-me o composto (risos...) e isso é que está a desvirtuar as coisas. Quanto a mim o defeito está na má utilização da máquina. Fazer o ensino à distância via internet. Isso é um chavão desgraçado. Então não há contacto pessoal? Isso desumaniza por completo. Fazem-se coisas bonitas, sem dúvida, mas nisto também se faz muita coisa que não tem nada de especial. Havia aquele slogan dos americanos (fazem muitas coisas que servem de exemplo, outras não, mas nisto das Técnicas e Ciências eles servem de exemplo senão não tinham o maior número de prémios Nobel em Ciência), sabe como era o slogan,... "publish or perish". E qual é o actual?... "publish and perish". A criatividade encontra-se abafada pela pressão em publicar.

A sua actividade não se limitou à Universidade, tendo sido inclusivé vereador da Câmara do Porto.

Dizia-se, e é verdade, que na época os membros da Câmara não eram eleitos; também depende do significado que se quer dar a eleito; no fundo eleger é escolher. Simplesmente, aqui na Câmara do Porto, na parte da vereação havia sempre um Professor Universitário. 0 Presidente da Câmara, que era nomeado, pedia ao Senhor Reitor a indicação de dois nomes. Sucede que quando fui para lá, tinha acabado de fazer o concurso para Catedrático, portanto o Reitor tinha o meu nome fresquinho. Além disso o vice-presidente tinha sido meu colega de curso, mas ainda levou algum tempo a convencer-me. Pensei, agora vamos ver se podemos fazer alguma coisa. E fui parar aos transportes colectivos.

O seu curriculum está pleno de distinções, o que significam para si?

Quer-se referir a alguma em particular? É que eu não tenho assim nenhuma em especial, algumas são praticamente automáticas. A única coisa que eu posso considerar uma distinção foi a condecoração inglesa. $\mathrm{O}$ que é facto é que estou há bastantes anos ligado ao British Council, desde a minha bolsa de estudo, que foi a única porta que se me abriu em 1949. Há um dever de gratidão. Quando foi decidido, devido a um corte de orçamento em Inglaterra, acabar com o Instituto Britânico do Porto, houve um movimento de Ingleses e Portugueses que criaram a Associação Luso-Britânica do Porto. Por acordo com o British Council, tivemos permissão para usar as instalações afim de manter o ensino e a parte cultural. As coisas começaram a mudar. A Associação Luso-Britânica ficou economicamente próspera, porque os dirigentes eram todos voluntários e tínhamos um tesoureiro que era uma pessoa fantástica, que administrava as coisas bem... e - British Council acabou por retomar a direcção. Nessa altura eu tinha a impressão que toda a gente, mesmo lá dentro, quando se falava no cultural pensava exclusivamente em artes plásticas ou dramáticas ou literatura, a ciência não era considerada. Eu consegui virar isso. Em vez de trazer uma pessoa de Inglaterra para fazer uma ou duas conferências, convidava-a a dar um curso breve de uma semana. O British Council pagava a viagem, a Associação a estada, e fizeram-se vários cursos assim. E parece que estranharam muito que a ciência passasse a ser também cultura (risos...), deve ser essa a origem disso.

Prof. João Cabral, o senhor é uma pessoa que acredita no futuro. Que conselho daria a um jovem que neste momento iniciasse agora a sua carreira.

$\mathrm{Na}$ investigação?

\section{Sim, na investigação.}

Penso que a primeira coisa seria escoIher o supervisor..

(risos...)

... se a pessoa é acessivel, disponível, que meios é que consegue pôr à disposição.

A entrevista já vai bem longa, gostaríamos de saber se o Professor deseja dizer alguma coisa para finalizar?

Tenho aquela frase batida, que a esperança é a última coisa a morrer

Notas:

${ }^{1}$ Autor de um livro de referência em Química Analítica. Ainda se usava no IST nos anos sessenta.

2 Professor Alberto Ralha, durante muitos anos Presidente do INIC.

${ }^{3} \mathrm{O}$ trabalho versava a determinação das constantes de dissociação do cianeto de mercúrio (II)

\section{João Luiz Leão Cabreira de Oliveira Cabral (Nota Biográfica)}

João de Oliveira Cabral nasceu em 14 de Julho de 1921, no Porto. É licenciado em Engenharia Químico-Industrial (1945) pela Faculdade de Engenharia da Universidade do Porto e Doutor em Engenharia QuímicoIndustrial (1951) pela mesma Faculdade. Iniciou a sua carreira docente na Faculdade de Ciências da Universidade do Porto tendo sido, sucessivamente, nomeado $2 .^{\circ}$
Assistente do 2. ${ }^{\circ}$ Grupo (Química) da 2. ${ }^{\circ}$ Seç̧ão (Ciências Fisico-Químicas) em 1946 e, $1 .^{\circ}$ Assistentente em 1951. Foi nomeado, precedendo concurso de provas públicas, Professor Extraordinário do 2. Grupo da 2. ${ }^{2}$ Secção, em 1965 e, Professor Catedrático, precedendo também concurso de provas públicas, em 1967. Exerceu funçōes de Director do Laboratório de Química da Faculdade de Ciências do Porto (de 1968 a 1970), Professor Secretário da
Faculdade de Ciências do Porto (de 1968 a 1971), Director da Biblioteca da Faculdade de Ciências do Porto (de 1971 a 1974) e Presidente do Conselho Científico da Faculdade de Ciências do Porto (1980). Jubilouse em 14 de Julho de 1991.

Ao longo da sua carreira, trabalhou na Faculty of Technology da Universidade de Manchester (mais tarde UMIST), em 1949 e 1950 como bolseiro do British Council, em polarografia de corantes azóicos sob ori- 
entação do Dr. H. A. Turner, no Departamento de Química Analítica do M.I.T. (1953), com o Prof. David Hume em técnicas polarográficas para a determinação de constantes de dissociação do cianeto de mercúrio(II) e, no Departamento de Química da Queen's University, Belfast, Irlanda do Norte, em 1963 e 1964 como bolseiro da Fundação Calouste Gulbenkian, com o Dr. S. Martin Nelson, em Química de Coordenação de complexos moleculares mistos de cobalto(II) com halogénios e aminopiridinas.

Ao longo dos 45 anos da sua actividade de docente, sempre em dedicação exclusiva à Universidade, regeu um grande número de cadeiras de diversas áreas da Química, tendo efectuado e orientado investigação nas áreas da Química Analítica e da Química Inorgânica de Compostos de Coordenação. Publicou um livro, diversos textos didácticos e algumas dezenas de artigos científicos em revistas da especialidade. A acção do Professor João Cabral no Departamento de Química da Faculdade de Ciências do Porto, fica marcada pela visão estratégica de futuro que teve nas décadas de 60 e 70, ao sentir a necessidade de criar condiçōes para que alguns dos membros mais jovens do Departamento fossem realizar trabalho de investigação e efectuar os seus doutoramentos em Universidades estrangeiras de reconhecida qualidade, na maioria dos casos no Reino Unido, dando assim possibilidade de o Departamento passar a ter docentes especializados em diversas áreas da Química, e de aí iniciarem novas linhas de investigação. A esta modernização e expansão cientifica do Departamento fica para sempre ligada o nome e acção do Prof. João Cabral, um dos seus grandes obreiros e, sem dúvida, o seu principal responsável.

É Membro Correspondente da Academia das Ciências de Lisboa (desde 1990), foi Membro da Comissão de Química do Conselho Científico das Ciências Exactas do Instituto Nacional de Investigação Científica (de 1982 até à extinção do INIC em 1992), Representante Nacional (de 1992 a 1994) e, posteriormente Membro Associado da Comissão II.2 - Nomenclatura de Química Inorgânica - da IUPAC (de 1995 a 1999), Fellow da IUPAC (desde 2000), Membro do Planning Committee das International Conferences on Coordination Chemistry (desde 1972), Chairman da 26th International Conference on Coordination Chemistry
(Porto, 1988). Foi Membro do Conselho Médico-Legal, por inerência, desde 1968 até à sua extinção. É Membro, há mais de 50 anos, da Sociedade Portuguesa de Química, Sócio Emeritus da American Chemical Society e da Royal Society of Chemistry, Sócio Fundador (1983) da Sociedade Portuguesa de Electroquímica, da qual foi Presidente (1986/87 e 1992/93) e Vice-Presidente (1984/85). Foi Vereador da Câmara Municipal do Porto (de 1968 a 1974) e nomeado Gestor da mesma Câmara Municipal (de 27 de Maio a 15 de Julho de 1974). Tem exercido várias funçōes na Direcção da Associação Luso-Britânica do Porto: Vogal (de 1969 a 1978), Secretário (de 1979 a 1992) e Presidente (desde 1993).

E Officer of The British Empire - OBE (1988). Em 1988 foram-lhe atribuidos o Diploma e Medalha do Instituto Kurnakov de Quimica Geral e Inorgânica da Ordem de Lenine da Academia das Ciências da URSS, "pela sua contribuição para o desenvolvimento da Química dos Compostos de Coordenação".

(Manuel A. V. Ribeiro da Silva)

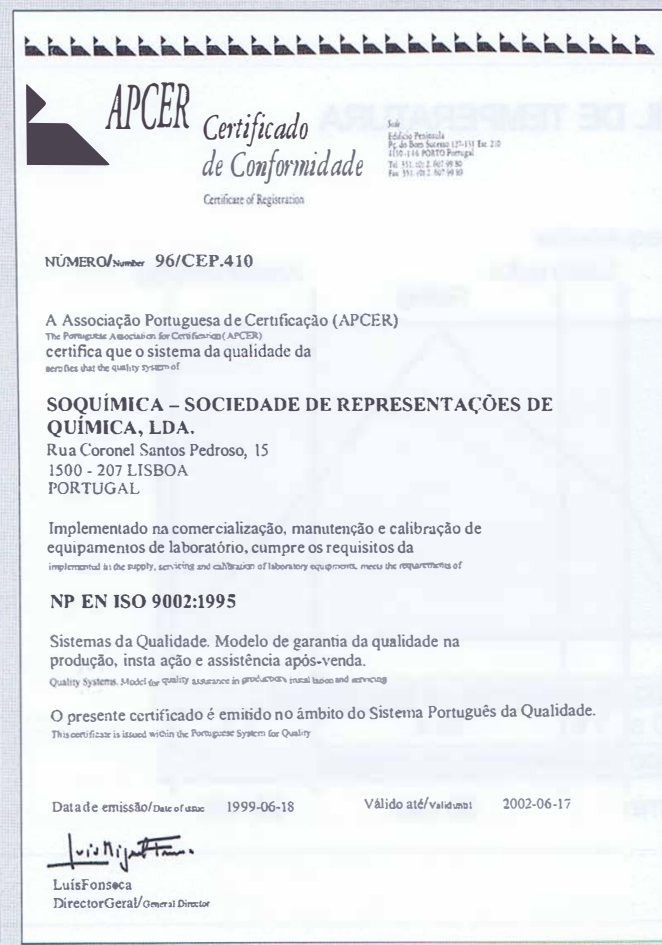

